\title{
Prevalence and factors associated with cigarette smoking among resident university students: A cross- sectional study from Bangladesh
}

\author{
Md. Sabbir Ahmed ${ }^{1}$, Abu Sayeed ${ }^{2}$, Ishrat Jahan³ ${ }^{3}$ Md. Forshed Dewan ${ }^{3}$, Sujan Kanti Mali ${ }^{4}$
}

Popul. Med. 2020;2(February):3

\section{CORRESPONDENCE TO}

Md. Sabbir Ahmed. Department of Community Health and Hygiene, Faculty of Nutrition and Food Science, Patuakhali Science and Technology University, Patuakhali 8602, Bangladesh. E-mail: sabbir.nfs@gmail.com

\section{KEYWORDS}

cigarette smoking, factors affecting cigarette smoking, resident university students

Received: 17 December 2019, Revised: 17 February 2020,

Accepted: 17 February 2020

\begin{abstract}
INTRODUCTION Previous studies have shown that the prevalence of cigarette smoking among university students is high, which may predispose students to various chronic diseases. Resident students are an interesting population to study because they are usually independent of their family and may be influenced by other factors. The objectives of this study were to assess the prevalence and factors associated with cigarette smoking among resident university students in Bangladesh.

METHODS A total of 360 resident university students were approached to participate in the study, in 2019 in Bangladesh. A two-stage cluster sampling method was used to select the participants and data were collected by using a pre-tested self-reported questionnaire. Logistic regression was applied with both crude and adjusted models.
\end{abstract}

RESULTS Overall prevalence of cigarette smoking was $32.6 \%$ with about half of male students being smokers (49.1\%) and only $2.4 \%$ of the females, with prevalence higher for those aged $21-23$ years (36\%). There was a significant association $(p<0.001)$ between students' cigarette smoking behavior and their maternal occupation, monthly expenditures, and living status with smokers. Students whose mothers were employed had higher odds of using cigarettes than students whose mothers were housewives (OR=3.4; 95\% CI: 1.7-6.8). Students who were sharing a room with a smoker had a higher risk of being a smoker (OR=9.7; 95\% CI: 4.9-19.0). CONCLUSIONS The results of this study provide interesting insights on tobacco use by resident university students in Bangladesh and will be useful during national policymaking on tobacco as well as for the tobacco-free campus movement of the universities.

\section{INTRODUCTION}

Tobacco smoking among young adults has become a global health concern ${ }^{1}$ as it affects different physiological systems and increases the risk of different forms of cancers ${ }^{2}$. Research shows that it reduces the life expectancy of male smokers by about 12 years and that of females by 11 years ${ }^{3}$. The ill health effects of smoking, particularly lung cancer, are most prevalent among people who start smoking at an early age and continue smoking into adulthood ${ }^{4}$. Smoking causes many deaths among smokers, and also among non-smokers who frequently are exposed to smoke ${ }^{1}$.
There are about 1.07 billion smokers worldwide, of whom 908 million are men and 162 million are women, with the majority from low- and middle-income countries ${ }^{1}$. In the USA, nearly 8 in 100 adults aged 18-24 years smoke cigarettes ${ }^{5}$. In England, about $14 \%$ of adults smoke, which is the main risk to their health ${ }^{6}$. The smoking prevalence among Bangladeshi adults is about $19 \%{ }^{1}$. A recent study among university students of Jahangirnagar University, Bangladesh, shows that $60 \%$ of the students smoke 7 . In another study conducted on university students of Sylhet division found that the prevalence of smoking is $37 \%$, while about half of the male 
students were smokers ${ }^{8}$.

From the literature, the majority of university students start smoking due to the influence of friends. Students who have more smoker friends are more likely to become smokers $^{7-9}$. They also start smoking by imitating their smoker family members ${ }^{7}$ and through curiosity ${ }^{7-9}$. The prevalence of cigarette smoking was found higher in students who live away from home and have higher living expenditures. Very few students report that a feeling of maturity, symbol of manliness and unhappy family environment as reasons for smoking ${ }^{9}$. In the case of resident students, prevalence is higher than in non-resident students as they are away from their family and home and may receive different influences than students who live with their families. The objectives of this study were to explore the prevalence and risk factors associated with cigarette smoking among resident students of a university in Bangladesh.

\section{METHODS}

\section{Study setting and participants}

A cross-sectional study was carried out among the resident university students of Patuakhali Science and Technology University, Bangladesh, from August to October 2019. There are six dormitories (halls) in this university and data were collected from each of the dormitories. The only inclusion criterion for the participants was being enrolled as a resident student of the respective hall. The sample size was calculated based on a single population proportion formula with the following considerations: prevalence of cigarette smoking (37\%) from a previous study carried out among the university students in Sylhet division of Bangladesh ${ }^{8}, 95 \%$ confidence level, $5 \%$ margin of error, and $10 \%$ non-response rate. A total of 360 students were asked to participate and completed data were collected from 355 students (response rate 98.6\%).

All study procedures were carried out following the guidelines of the Helsinki Declaration (1975). Written ethical approval was obtained from the Institutional Ethical Committee of Patuakhali Science and Technology University (Ref. PSTU/IEC/2019/03). Written informed consent was obtained from the participants before data collection. Participants were informed that their participation was voluntary and they had the right to withdraw from the study at any time. They were also assured of the confidentiality and anonymity of their data.

\section{Data collection}

Data were collected using a pre-tested self-reported questionnaire. Two-stage cluster sampling was used to select the participants. Firstly, a list of each room number was prepared for each dormitory. Rooms were selected by a systematic random sampling technique. Secondly, two students were selected from each of the selected rooms by using the random sample method. After selecting the participants, a consent form was given to them to read, sign and return back to the data collector. After having the signed consent form, the participants were requested to fill in the questionnaire, which took approximately 8-10 minutes for the participants to complete.

\section{Operational definitions \\ Smoker}

A student who smoked at least one cigarette stick per day over a period of 6 months was considered a smoker in this study. This definition was also used in a previous study 8 .

\section{Non-smoker}

A student who never smoked a cigarette or was a smoker previously but stopped for at least one year before was considered a non-smoker in this study. This definition was also used in a previous study8.

\section{Statistical analysis}

Descriptive statistics were performed to calculate the frequencies and percentages of different sociodemographic variables. Chi-squared test was used for testing the association between sociodemographic variables and outcome variables (smoking status), and the association was considered significant at $\mathrm{p}<0.05$. Both bivariate and multivariate logistic regression models were used to identify the potential factors of cigarette smoking among the students and the significance level of $p$-values was set at $<0.05$. Crude and adjusted analyses are presented. Data were analyzed using IBM SPSS 23 (windows version).

\section{RESULTS}

Table 1 shows the descriptive statistics of the study participants. The average age of the students was 21.5 years $(S D=1.7)$ and the majority of the participants were male. The cigarette smoking prevalence for the 355 participants was $32.6 \%$. As seen in Table 1, almost half of the male students were smokers $(49.1 \%)$ while only $2.4 \%$ of females were smokers with the prevalence higher for those aged 21-23 years (36\%). Smoking prevalence was also higher among the students from the engineering faculty (46.4\%) and 4 th year students (42.6\%). There was no association found between the parental educational status and smoking behavior of the students. More than half of the students (54.7\%) that spent more ( $>5000$ BDT; exchange rate 1000 BDT about 12 US\$) money on living expenses were found to be smokers compared with others. The analysis also shows that smoking behavior was significantly associated with parental smoking, peer smoking status, and living with smokers.

Results from the regression analysis showed that there was a significant association between mother's occupation and cigarette smoking of the students. Students whose mothers were employed had higher odds of using cigarettes than students whose mothers were housewives (crude $\mathrm{OR}=2.3$; 95\% CI: 1.4-3.8). It remained higher after adjusting for covariables (AOR=3.4; 95\% CI: 1.7-6.8). Respondents who spent $>5000$ BDT per month for living expenses had 
Table 1. Sociodemographic characteristics of the students by their smoking status, Bangladesh $2019(\mathrm{~N}=355)$

\begin{tabular}{|c|c|c|c|c|c|}
\hline \multirow[t]{2}{*}{ Characteristics } & \multirow{2}{*}{$\frac{\text { Students }}{\mathrm{n}}$} & \multicolumn{2}{|c|}{ Smoking status } & \multirow[t]{2}{*}{$\chi^{2}$} & \multirow[t]{2}{*}{$\mathbf{P}$} \\
\hline & & $\begin{array}{l}\text { Smoker } \\
\text { n (\%) }\end{array}$ & $\begin{array}{c}\text { Non-smoker } \\
\text { n (\%) }\end{array}$ & & \\
\hline \multicolumn{6}{|l|}{ Age (years) } \\
\hline $18-20$ & 108 & $27(25.0)$ & $81(75.0)$ & 4.15 & 0.125 \\
\hline $21-23$ & 189 & $68(36.0)$ & $121(64.0)$ & & \\
\hline $24-26$ & 58 & $21(36.2)$ & $37(63.8)$ & & \\
\hline \multicolumn{6}{|l|}{ Sex } \\
\hline Male & 230 & $113(49.1)$ & $117(50.9)$ & 80.39 & $<0.001$ \\
\hline Female & 125 & $3(2.4)$ & $122(97.6)$ & & \\
\hline \multicolumn{6}{|l|}{ Study area } \\
\hline Agricultural science & 254 & $74(29.1)$ & $180(70.9)$ & 5.50 & 0.064 \\
\hline Engineering & 28 & $13(46.4)$ & $15(53.6)$ & & \\
\hline Business studies & 73 & $29(39.7)$ & $44(60.3)$ & & \\
\hline \multicolumn{6}{|l|}{ Year of study } \\
\hline First & 84 & $25(29.8)$ & $59(70.2)$ & 5.85 & 0.210 \\
\hline Second & 81 & $27(33.3)$ & $54(66.7)$ & & \\
\hline Third & 55 & $19(34.5)$ & $36(65.5)$ & & \\
\hline Fourth & 68 & $29(42.6)$ & $39(57.4)$ & & \\
\hline Master's & 67 & $16(23.9)$ & $51(76.1)$ & & \\
\hline \multicolumn{6}{|l|}{ Father's education level } \\
\hline $0-4$ & 37 & $13(35.1)$ & $24(64.9)$ & 0.19 & 0.909 \\
\hline $5-9$ & 62 & $21(33.9)$ & $41(66.1)$ & & \\
\hline$\geq 10$ & 256 & $82(32.0)$ & $174(68.0)$ & & \\
\hline \multicolumn{6}{|l|}{ Father's occupation } \\
\hline Agriculture-based & 37 & $12(32.4)$ & $25(67.6)$ & 0.56 & 0.967 \\
\hline Labor & 5 & $2(40.0)$ & $3(60.0)$ & & \\
\hline Business & 106 & $32(30.2)$ & $74(69.8)$ & & \\
\hline Job & 149 & $50(33.6)$ & $99(66.4)$ & & \\
\hline Others & 58 & $20(34.5)$ & $38(65.5)$ & & \\
\hline \multicolumn{6}{|l|}{ Mother's education } \\
\hline $0-4$ & 17 & 7 (41.2) & $10(58.8)$ & 1.31 & 0.518 \\
\hline $5-9$ & 154 & $46(29.9)$ & $108(70.1)$ & & \\
\hline$\geq 10$ & 184 & $63(34.2)$ & $121(65.8)$ & & \\
\hline \multicolumn{6}{|l|}{ Mother's occupation } \\
\hline Homemaker & 271 & $76(28.0)$ & $195(72.0)$ & 11.16 & 0.001 \\
\hline Working outside home & 84 & $40(47.6)$ & $44(52.4)$ & & \\
\hline \multicolumn{6}{|l|}{ Permanent residence } \\
\hline Rural area & 207 & $64(30.9)$ & $143(69.1)$ & 0.69 & 0.404 \\
\hline Urban area & 148 & $52(35.1)$ & $96(64.9)$ & & \\
\hline \multicolumn{6}{|c|}{ Household monthly income (BDT) } \\
\hline$<15000$ & 59 & $19(32.2)$ & $40(67.8)$ & 5.12 & 0.077 \\
\hline $15000-30000$ & 165 & $45(27.3)$ & $120(72.7)$ & & \\
\hline$>30000$ & 131 & $52(39.7)$ & $79(60.3)$ & & \\
\hline \multicolumn{6}{|c|}{ Monthly expenditure (BDT) } \\
\hline$<4000$ & 44 & $2(4.5)$ & $42(95.5)$ & 41.91 & $<0.001$ \\
\hline $4000-5000$ & 205 & $56(27.3)$ & 149 (72.7) & & \\
\hline$>5000$ & 106 & $58(54.7)$ & $48(45.3)$ & & \\
\hline
\end{tabular}


Table 1. Continued

\begin{tabular}{|c|c|c|c|c|c|}
\hline \multirow[t]{2}{*}{ Characteristics } & \multirow{2}{*}{$\begin{array}{c}\text { Students } \\
\mathbf{n}\end{array}$} & \multicolumn{2}{|c|}{ Smoking status } & \multirow[t]{2}{*}{$\chi^{2}$} & \multirow[t]{2}{*}{$\mathbf{P}$} \\
\hline & & $\begin{array}{l}\text { Smoker } \\
\text { n (\%) }\end{array}$ & $\begin{array}{c}\text { Non-smoker } \\
\text { n (\%) }\end{array}$ & & \\
\hline \multicolumn{6}{|c|}{ Parental smoking } \\
\hline Yes & 94 & $41(43.6)$ & $53(56.4)$ & 6.95 & 0.008 \\
\hline No & 261 & 75 (28.7) & $186(71.3)$ & & \\
\hline \multicolumn{6}{|l|}{ Smoker friend } \\
\hline Yes & 297 & $114(38.4)$ & $183(61.6)$ & 26.92 & $<0.001$ \\
\hline No & 58 & $2(3.4)$ & $56(96.6)$ & & \\
\hline \multicolumn{6}{|c|}{ Smoker roommate } \\
\hline Yes & 87 & $65(74.7)$ & $22(25.3)$ & 92.57 & $<0.001$ \\
\hline No & 268 & $51(19.0)$ & $217(81.0)$ & & \\
\hline
\end{tabular}

BDT: Bangladeshi Taka (1000 BDT about 12 US\$).

Table 2. Factors associated with cigarette smoking among students, Bangladesh 2019 (N=355)

\begin{tabular}{|c|c|c|c|c|c|c|}
\hline \multirow[t]{2}{*}{ Factors } & \multicolumn{3}{|c|}{ Crude } & \multicolumn{3}{|c|}{ Adjusted $^{\mathrm{a}}$} \\
\hline & OR & $95 \%$ CI & $\mathbf{p}$ & AOR & $95 \% \mathrm{CI}$ & $\mathbf{p}$ \\
\hline \multicolumn{7}{|l|}{ Mother's occupation } \\
\hline Homemaker & 1.0 & & & & & \\
\hline Working outside home & 2.3 & $1.4-3.8$ & 0.001 & 3.4 & $1.7-6.8$ & $<0.001$ \\
\hline \multicolumn{7}{|c|}{ Monthly expenditure (BDT) } \\
\hline$<4000$ & 1.0 & & & & & \\
\hline $4000-5000$ & 7.8 & $1.8-33.6$ & $<0.001$ & 10.0 & $2.1-46.0$ & 0.003 \\
\hline$>5000$ & 25.3 & $5.8-110.2$ & $<0.001$ & 34.1 & $7.1-163.1$ & $<0.001$ \\
\hline \multicolumn{7}{|l|}{ Parental smoking } \\
\hline Yes & 1.9 & $1.1-3.1$ & 0.009 & 1.7 & $0.9-3.0$ & 0.610 \\
\hline No & 1.0 & & & & & \\
\hline \multicolumn{7}{|l|}{ Smoker friend } \\
\hline Yes & 17.4 & $4.1-72.8$ & $<0.001$ & 7.4 & $1.5-36.4$ & 0.013 \\
\hline No & 1.0 & & & & & \\
\hline \multicolumn{7}{|l|}{ Smoker roommate } \\
\hline Yes & 12.5 & $7.0-22.2$ & $<0.001$ & 9.7 & $4.9-19.0$ & $<0.001$ \\
\hline No & 1.0 & & & & & \\
\hline
\end{tabular}

a Variables adjusted for all the variables in the Table.

a higher risk of being a smoker (crude OR=25.3; 95\% CI: 5.8-110.2) and it remained higher after adjusting for the variables (AOR=34.1; 95\% CI: 7.1-163.1). The association was highly significant in both cases. The analysis also showed that students who are currently sharing their room with a smoker had a higher risk of being a smoker (crude $\mathrm{OR}=12.5$; 95\% CI: 7.0-22.2) and the odds of being a smoker remained higher after adjusting for the variables (AOR=9.7; 95\% CI: 4.9-19.0), both associations were statistically significant (Table 2).

\section{DISCUSSION}

In our present survey on cigarette smoking behavior among the resident university students in Bangladesh, the overall prevalence of cigarette smoking was $32.7 \%$, lower than in previous studies conducted among the university students in Sylhet division ${ }^{10}$ and medical students in Bangladesh ${ }^{11}$. However, the prevalence was lower than given in the Global Adult Tobacco Survey (GATS) report, where the overall prevalence of tobacco smoking in Bangladesh was $23.0 \%{ }^{12}$, suggesting a higher prevalence of smoking among university 
students in Bangladesh than among young adults in general. This study also reported that nearly half of the male students smoke, in line with the GATS ${ }^{12}$ and the study done in Sylhet ${ }^{10}$. The prevalence was higher than that reported in nearby countries such as India $(20.4 \%)^{13}$, Pakistan $(26.1 \%)^{14}$, Nepal $(33.6 \%)^{15}$ and Malaysia (42.1\%) ${ }^{16}$. The present study found that the prevalence of cigarette smoking among students who come from an urban area is higher than for those who come from a rural area. The most important independent factor associated with cigarette smoking was having smoking friends and/or smoking roommates; similar results were reported from different regions of the world ${ }^{17}$. We also found that smoking among university students was correlated with parental smoking and this finding is consistent with other studies ${ }^{17}$. The prevalence of smoking by mother's profession as well as by monthly expenditure was significantly different, which may be related to higher levels of family income as students may have more money available ${ }^{10}$. This study also found that the risk of being a smoker is 9.7 times higher for those who have a smoker roommate compared with those with a non-smoker roommate - without excluding the likelihood that smokers may select each other as roommates. The risk of becoming a smoker was found to be 3.4 times higher among students whose mothers worked outside the home than those whose mothers were housewives. Respondents whose parents were smokers were more likely to be smokers.

\section{Limitations}

Our present study is not without limitations. Firstly, it was limited to a sample of resident university students and did not include students from all of Bangladesh's universities. In addition, negative responses from students who smoke may have underestimated the prevalence of smoking. Smoking risk and predictors among university students could be measured more precisely if samples were to be collected from different universities in Bangladesh. Lastly, as this study is cross-sectional, we can only assess associations and not causality.

\section{CONCLUSIONS}

The findings of our study show that cigarette smoking prevalence is higher among resident university students than in the general population and identified a number of parameters associated with higher odds of being a smoker. Our findings will contribute to knowledge of cigarette use among Bangladeshi university students. These findings may also be useful for policymaking and for the tobacco-free campus movement.

\section{REFERENCES}

1. World Health Organization. WHO report on the global tobacco epidemic, 2019: Offer help to quit tobacco use. Geneva, Switzerland: World Health Organization; 2019. https://apps.who. int/iris/bitstream/handle/10665/326043/9789241516204- eng.pdf?ua=1. Accessed December 17, 2019.

2. How does smoking affect the body? Medical News Today. https://www.medicalnewstoday.com/articles/324644.php. Accessed December 7, 2019.

3. American Cancer Society. Health Risks of Smoking Tobacco. American Cancer Society. https://www.cancer.org/cancer/ cancer-causes/tobacco-and-cancer/health-risks-of-smokingtobacco.html. Published November 15, 2018. Accessed December 7, 2019.

4. Elders MJ, Perry CL, Eriksen MP, Giovino GA. Preventing Tobacco Use among Young People: A Report of the Surgeon General. Am J Public Health. 1994;84(4):543-547. doi:10.2105/ajph.84.4.543

5. National Center for Chronic Disease Prevention and Health Promotion (US) Office on Smoking and Health. The Health Consequences of Smoking-50 Years of Progress: A Report of the Surgeon General. Atlanta (GA): Centers for Disease Control and Prevention (US); 2014. PMID:24455788.

6. Barr S. England could become 'smoke-free' by 2030 under new government pledge. The Independent. https:// www.independent.co.uk/life-style/health-and-families/ smoking-ban-uk-end-cigarettes-tobacco-health-greenpaper-a9016636.html. Published July 23, 2019. Accessed December 17, 2019.

7. Hossain S, Hossain S, Ahmed F, Islam R, Sikder T, Rahman A. Prevalence Tobacco Smoking and Factors Associated with the Initiation of Smoking among University Students in Dhaka, Bangladesh. Cent Asian J Glob Health. 2017;6(1):244. doi:10.5195/cajgh.2017.244

8. Hassan MS, Hossain MK, Khan HTA. Prevalence and predictors of tobacco smoking among university students in Sylhet Division, Bangladesh. International Health. 2019;11(4):306-313. doi:10.1093/inthealth/ihy091

9. Tarafdar MMA, Nahar S, Rahman MM, Hussain SMA, Zaki M. Prevalence and Determinants of Smoking among the College Students in Selected District of Bangladesh. Bangladesh Medical Journal. 2009;38(1):3-8. doi:10.3329/bmj.v38i1.3579

10. Kamal SM, Islam MA, Rahman MA. Sociopsychological correlates of smoking among male university students in Bangladesh. Asia Pac J Public Health. 2011;23(4):555-567. doi:10.1177/1010539509350495

11. Karim M, Farah S, Parash TH. Smoking prevalence, knowledge and attitudes among medical students in Dhaka, Bangladesh. Borneo Journal of Medical Sciences. 2016;10(1):84-91.

12. World Health Organization . Global adult tobacco survey: Bangladesh Report 2009. Dhaka, Bangladesh: World Health Organization, Country Office for Bangladesh; 2009. doi:10.13140/RG.2.1.1075.1526

13. Lalithambigai G, Rao A, Rajesh G, Shenoy R, Pai MBH. Predictors of cigarette smoking among young adults in Mangalore, India. Asian Pac J Cancer Prev. 2016;17(1):4550. doi:10.7314/apjcp.2016.17.1.45

14. Asif HM, Akhtar N, Sultana S, et al. Prevalence and factors related to cigarette smoking initiation and use among university students of Bahawalpur Pakistan: a cross sectional 
study. RADS Journal of Pharmacy and Pharmaceutical Sciences. 2017;5(3):11-16. http://jpps.juw.edu.pk/index. php/jpps/article/view/142. Accessed December 2019.

15. Pradhan PMS, Niraula SR, Ghimire A, Singh SB, Pokharel PK. Tobacco use and associated factors among adolescent students in Dharan, Eastern Nepal: a cross-sectional questionnaire survey. BMJ Open. 2013;3(2):e002123. doi:10.1136/bmjopen-2012-002123

16. Al-Naggar RA, Bobryshev Y V, Mohd N, Nor AB. Lifestyle practice among Malaysian university students. Asian Pac J Canc Prev. 2013;14(3):1895-1903. doi:10.7314/apjcp.2013.14.3.1895

17. Ngahane BHM, Ekobo HA, Kuaban C. Prevalence and determinants of cigarette smoking among college students: a cross-sectional study in Douala, Cameroon. Arch Public Health. 2015;73(1):47. doi:10.1186/s13690-015-0100-1 